Boise State University

ScholarWorks

9-1-2009

\title{
Women Bound to Be Active: One Year Follow-Up to an Innovative Pilot Intervention to Increase Physical Activity and Self-Worth in Women
}

Jennifer L. Huberty

University of Nebraska Omaha

Jamie Vener

Southern Oregon University

Laura Schulte

University of Nebraska Omaha

Sara M. Roberts

University of Nebraska Medical Center

Beth Stevens

University of Nebraska Medical Center

See next page for additional authors 
Authors

Jennifer L. Huberty, Jamie Vener, Laura Schulte, Sara M. Roberts, Beth Stevens, and Lynda Ransdell 


\title{
Women Bound to Be Active: One Year Follow-Up to an Innovative Pilot Intervention to Increase Physical Activity and Self-Worth in Women
}

\author{
Jennifer L. Huberty \\ University of Nebraska Omaha \\ Jamie Vener \\ Southern Oregon University \\ Laura Schulte \\ University of Nebraska Omaha
}

\author{
Sara M. Roberts \\ University of Nebraska Medical Center \\ Beth Stevens \\ University of Nebraska Medical Center \\ Lynda Ransdell \\ Boise State University
}

Key Words: Health, exercise, adherence, female, adult, group-based, social support

\begin{abstract}
The purpose of this investigation was to assess the effectiveness of a lifestyle intervention (a women's book club; Women Bound to be Active) in promoting long-term physical activity (PA). Thirty-five women (26-70 years; mean age 50.6 years) completed the 8-month intervention and participated in the one-year follow-up. At follow-up, PA returned to baseline levels; however, self-worth and body mass index significantly improved. Women were more knowledgeable about PA at follow-up; however, they failed to maintain PA after the intervention. Components of the intervention were effective in improving self-worth and lowering BMI at one-year follow-up. To enhance longterm PA adherence continued research and intervention modifications are needed.

\section{Introduction}

The benefits of regular physical activity (PA) are well known and include a decreased risk for many chronic diseases such as heart disease, type II diabetes, most cancers, and osteoporosis (Hahn, Teuesch, Rothenberg, 1998; United States Department of Health and Human Services (USDHHS), 1996). Physical activity recommendations suggest 30 minutes of moderate intensity PA should be accumulated on most if not all days of the week to achieve health benefits (USDHHS, 2008). Despite these straightforward recommendations, many adults never realize the benefits of regular PA. Approximately 40-60\% of adults quit participation in PA within 3 to 6 months of starting, often before most health benefits can be realized (Ainsworth, 2000; Annesi, 2000). Women are less active than men. In $2000,43 \%$ of US adult women were classified as sedentary. Certain factors contribute to inactivity (i.e., time, lack of motivation, no support etc.) (Eyler \& Vest, 2002); however, efforts to determine what will help women sustain PA over time remain an area of interest and a knowledge gap in the area of public health (McAuley, Jerome, Elavsky, Marquez, \& Ramsey, 2003; Wilbur, Miller, Chandler, \& McDevitt, 2003).

Over the past decade, researchers have studied adherence using a number of approaches (intermittent vs. continuous, lifestyle vs. structured programs) in a variety of settings (group based vs. home-based), and for various lengths of time (2-24 months) (Blair 1992; Dunn 1999; Epstein \& Roemmich, 2001). In most studies, regardless of the approach, PA adherence decreased over time (Cox, Burke, Beilin, Derbyshire, Grove, \& Blanksby, 2008)King and colleagues (1995) assessed long-term adherence to high- and low-intensity PA in group- and home-based exercise programs and determined that participants engaged in home-based low-intensity PA had better adherence than those in the higher intensity group-based exercise program when the length of the program was the same (2 years). Follow-up over the 2 years included phone contact from a health professional to remind participants to mail their activity logs, with exercise frequency, intensity, and duration. No qualitative component was used to explore factors contributing to adherence (or lack thereof) at the end of the two years.
\end{abstract}


Dunn and colleagues (1999) reported PA adherence to a 24-month intervention with both lifestyle and structured exercise groups. Both groups had similar increases in PA at 6-months and similar decreases in PA at 24-months, but increased energy expenditure at 24-months compared to baseline. These findings suggest that lifestyle interventions may be as effective as structured interventions for promoting long-term PA adherence.

Most researchers agree that lifestyle-based interventions in which women are free to choose their respective activities and times for activities throughout the day are as effective as structured programs, particularly in longterm interventions (Blair 1992; Dunn 1999; Epstein \& Roemmich, 2001). Recently Huberty et al. (2008) reported on the feasibility of a book club intervention to increase PA and self-worth in a group of women. The intervention was guided by the Transtheoretical Model and the Social Cognitive Theory and included the use of readings and group discussions related to health behavior. Women read both fiction and non-fiction books (not necessarily related to PA) and used a work-book (written by the principal investigator) to help guide their group discussions. Women were not provided a structured exercise intervention. Instead, they were given tools to facilitate participation in PA and were encouraged to be active on their own. After the intervention, women reported higher perceptions of self-worth and increased PA (Huberty et al., 2008). This study provided evidence that lifestyle-based interventions specifically tailored to women (i.e., a book club) may help increase PA, especially when psychosocial components such as self-worth/self-esteem are considered.

The role of psychosocial factors in determining PA adherence has been extensively studied. Researchers have frequently suggested that social contacts and support are an important factor in program adherence (McAuley, 2003; Rhodes, 2001). According to a literature review by White and colleagues (2005), women who were supported in their behavior (by friends, family, health professional contact) to be physically active (were more likely to adhere to PA. Self-efficacy is also a major contributor to PA adherence in women and has been consistently reported by McAuley and colleagues (McAuley, 1993; McAuley, Mihalko, Bane, 1997; McAuley et al., 2003; McAuley, Morris, Motl, Konopack, \& Elavsky, 2007).

Another potential psychosocial contributor to adherence in women is self-esteem. Self-esteem is recognized for its positive influence on health behaviors (Levy \& Ebbeck, 2005). Self-esteem is multidimensional and hierarchal and individuals have multiple self-concepts and feelings of esteem in a variety of domains (academic, emotional, social, and physical). For example, self-esteem in the physical domain is comprised of specific perceptions of physical self which is influenced by other physical contexts (Fox, 2000; Levy \& Ebbeck, 2005; Sonstroem, 1997). A number of studies have reported that for women, PA participation and self-esteem (particularly the physical sub-domain) are correlated and contribute to adherence to PA (McAuley et al., 1997; McAuley \& Blissmer, 2000). Often used interchangeably with self-esteem, self-worth may also contribute to women's PA adherence (Elavsky 2009; Huberty et al., 2008). In a study by Huberty and colleagues (2008) predictors of women's continued activity one to three years after a 12-week intervention was examined.

Qualitative methodology was used to determine that women who remained active upon completion of their intervention did so for reasons related to their self-worth. Women reported that valuing themselves and their quality of life was more important than other factors that may typically facilitate PA such as weight and appearance change (Huberty et al., 2008). This was one of the few studies to assess long-term adherence to PA with no contact until follow-up. More studies such as these are needed to further substantiate the findings related to PA adherence in women.

Although these previously mentioned findings have contributed significantly to the PA literature, several key elements need to be explored. First, in most studies, some form of contact with participants after the intervention, prior to follow-up, has been used to encourage adherence. Few studies have investigated whether ceasing contact with participants upon completion of an intervention will lead to enhanced self-sufficiency in maintaining PA. Segar, Jayaratne, Hanlon, and Richardson (2002) reported maintenance of PA in women who participated in a 6week cognitive/empowerment based intervention nine months after the intervention was over. The researchers had no contact with the participants after the 6-week intervention. Long-term follow-up to PA interventions that do not include contact with participants is required to identify factors that contribute to independent, self-sufficient adoption of a physically active lifestyle. 
A second element that needs further exploration is the use of both qualitative and quantitative inquiry to elucidate meaningful and applicable information about why women adhere to long-term PA. Given the complexity of behavior change, innovative research that integrates mixed methodologies (e.g., integration of quantitative and qualitative methods) is warranted. When using mixed methodological approaches: both inductive and deductive reasoning can be applied; quantitative findings can be used to illuminate qualitative findings and vice versa; exploratory and confirmatory approaches can be applied simultaneously; and both observational and empirical data can be collected and analyzed (Berg, 2007; Onwuegbuzie \& Leech, 2005). When applied to PA research, the use of qualitative inquiry may help to supplement quantitative data by providing insight into thoughts and feelings related to long-term PA participation and elaboration about feelings of self-worth or other psychosocial factors.

Given the need to identify long-term determinants of PA in women, the purpose of this longitudinal study was to follow-up on previously reported findings in participants enrolled in a lifestyle-based book club intervention (Women Bound to Be Active) (Huberty et al., 2008).

Methods

\section{Participants}

Eligible participants were women who had completed the Women Bound to Be Active (WBA) program. Women were originally recruited through the Internet (website for PA opportunities in the local community), advertisements at local grocery stores, coffee shops, and a newspaper advertisement. Women who replied to the ads $(\mathrm{N}=100)$ were asked questions to identify their stage of change for PA using the Physical Activity Stage of Change questionnaire (Marcus, Rossi, Selby, Niaura, \& Abrams, 1992) which assessed current stage of change relative to physical activity. Stages ranged from precontemplation (not thinking about exercise at all) to maintenance (participates in exercise regularly). Participants in this study were only included if they were categorized in stages 2 or 3 (contemplation or preparation, respectively). The Physical Activity Stages of Change questionnaire is reliable and valid in adult populations (Marcus et al., 1992). Women were included in the WBA intervention if they were: (1) at least 19 years of age and (2) in the contemplation or preparation stages of the Transtheoretical Model (stages of change) (Marcus, et al., 1992). Fifty-five adult women (46.89 \pm 11.33 yrs) had originally met the inclusion criteria for the feasibility study, and 45 women completed the eight-month intervention. WBA is a PA book club that represents a creative and effective theory-based approach to empowering women to be more active through cognitive behavior change (Huberty et al., 2008). WBA took place in three locations in Omaha, Nebraska and one location in Harrisonburg, Virginia. Women attended weekly meetings for the first half of the program (months 1-4) and twice monthly for the second half (months 5-8). Meetings were based upon a syllabus and reading materials (fiction and/or non-fiction books, and a workbook written by the first author). Discussion was generated from the reading and personal experiences women were having or had related to changing their behaviors to be more physically active. Women were encouraged to participate in lifestyle based activity that they enjoyed but were not given a structured exercise program. For a complete summary of the program, see Huberty et al., 2008.

One year after completing the WBA intervention, participants were sent a packet of information that included: 1) an informational letter notifying them that a WBA investigator would be contacting them within a week to set up a telephone interview, 2) a copy of the questions so that they would have time to prepare their answers, and 3) questionnaires that they had completed during the feasibility study to complete again. The letter served as the informed consent that was approved by the Institutional Review Board at the University of Nebraska Omaha, and listed the purpose of the follow-up study and what would occur during the interview process. Additionally, the letter instructed participants to complete the questionnaires and send them back in the pre-addressed, postage-paid envelope. Of the 45 women in the feasibility study, 35 agreed to participate in a follow-up with 32 completing interviews and 26 completing all questionnaires (See Figure 1).

\section{[INSERT FIGURE 1 HERE]}

\section{Instrumentation \& Study Procedures}

All questionnaires administered were the same questionnaires participants had completed pre and post intervention during the feasibility study. All but one questionnaire was administered through the mail. The 7-day recall was administered over the phone during the interview. 
Women Bound to Be Active Health Status Questionnaire

The health status questionnaire (modified standard demographic questionnaire) was used to determine general demographics, medical history, and other health related behaviors (Howley \& Franks, 1992). The participant's weight and height (kilograms and meters, respectively) were self-reported and were assessed at baseline and again at follow-up to determine Body Mass Index (BMI- $\mathrm{kg} / \mathrm{m}^{2}$ ).

Adult Self Perception Profile: General Self-Worth

Self-worth was assessed using the Global Self-Worth Scale of the Adult Self-Perception Profile (Messer \& Harter, 1986). This scale used nine items to measure global perceptions of self-worth independent of any particular domain. An example of an item used in the self-worth scale is, "Some adults are dissatisfied with themselves BUT other adults are satisfied with themselves." Answers include "really true for me", "sort of true for me," and "not really true for me." Higher scores on the questionnaire indicate higher self-worth. The reliability estimate (Cronbach’s alpha) for this scale, in both homemakers and working women was .87 (Messer \& Harter, 1986).

Seven Day Recall \& Qualitative Interviews

Phone interviews were scheduled at participants' convenience and audio recorded by the investigator. Participants were asked about their PA participation using the Seven Day Recall. Each day was broken down into PA participation in the morning, afternoon, and evening and each activity was rated by the participant as being moderate, hard, or very hard in intensity. The total minutes of daily activity were added up along with minutes spent in stretching, strength training, and sleeping. Reliability and validity of this instrument has been previously reported (Gross, Sallis, Budno, Roby, \& Nelson, 1990: Jacobs, Ainsworth, Hartman, \& Leon, 1993).

After the PA recall was administered, participants were asked questions related to PA adherence and their participation in WBA (See Table 1). These questions were open-ended to allow participants to explain their experiences with PA and the program in their own words. The non-directive nature of open-ended questions enhances validity as informants articulate their experiences, rather than conform responses to pre-determined categories imposed by the researcher (Cicourel, 1982 as cited in Saks \& Allsop, 2007). Each interview lasted approximately 30 to 60 minutes and followed a script that was approved by the IRB. In addition to interview notes taken by the investigator, interviews were audio recorded to assure accuracy of the data.

\section{[INSERT TABLE 1 HERE]}

\section{Data Analysis \\ Qualitative}

The interviews were transcribed and identifiers were removed prior to analysis. Interview data were analyzed by the research team using an integrated approach that employed both inductive (ground up) and deductive development and organization of codes (Bradley, Curry \& Devers, 2007). Using interview notes taken by the investigator, the research team developed a coding structure which included key conceptual domains and participant perspectives. Minor modifications were made to this coding structure during final analysis process. The research team included two coders, who developed and applied the codes in a sequential fashion, using a five-stage framework approach (Pope, Ziebland \& Mays, 2000). The initial coder used immersion to become familiar with the data and to identify a preliminary coding structure and analysis. The second coder elaborated on the initial coding structure and systematically applied it to all transcribed responses. After coding, both coders of the research team reviewed the coding reports and analysis to ensure agreement. Data were coded and analyzed using NVivo qualitative analysis software (QSR NVivo 7).

\section{Quantitative}

Repeated-measures analyses of variance (ANOVAs) were used with the following dependent variables: self-worth, PA, and BMI. The repeated-measures factor was time with three levels (baseline, post; 8-months, and follow-up; 20-months). An alpha level of .05) was employed for the ANOVAs to indicate statistical significance. Follow-up Tukey pairwise mean comparison tests were used to investigate significant ANOVAs. Cohen's $d$ was calculated to compute effect sizes for significant pairwise mean differences. 


\begin{abstract}
Results
Findings from WBA feasibility study have been previously reported elsewhere (Huberty et al., 2008). Thirty five women (mean age of 50.6 years) participated in the follow-up; 91\% of these women were Caucasian (Table 2).
\end{abstract}

\title{
[INSERT TABLE 2 HERE]
}

For each variable reported, the sample size varied based on participant response (Figure 1).

\section{Participant's Experiences}

The aspect that most women liked about WBA was the social support that the group atmosphere provided and the increased motivation they received from their peers (65\%, $\mathrm{n}=20$ of 31 responding).

\section{"I really enjoyed the women in the group .... I really miss the social thing and having it involve physical activity."}

Other program attributes that participants liked included: 1) increased knowledge (i.e., participants felt that they were more aware about how to be active and could incorporate PA into their busy schedules (32\%, 10 of 31 responding), and 2) additional elements of the program including books (30\%, 9 out of 31 responding) and ensuing discussion, access to health promotion professionals, and introduction to pedometers (23\%, 7 of 31 responding).

When asked about what participants disliked about the program, a number of women reported that they disliked nothing about the program, though most did not elaborate on this. Some made suggestions for program improvement related to content of program (e.g., more books, PA incorporated into meetings), structure of program (e.g., program should have been longer), and group composition (e.g., more diverse, similar in age).

\section{Participants' Behavior Change}

Participants significantly increased their PA level from baseline to post $(d=1.36)[F(2,44)=10.697, p=<.0005$ ] (Table 3). No significant difference in PA was observed from baseline to follow-up or from post-intervention to follow-up. In addition, BMI significantly decreased from baseline to post-intervention $(d=.83)$ and from baseline to follow-up $(d=1.10)[F(2,46)=7.869, p=.001]$. BMI did not decrease significantly from post-intervention to followup.

\section{[INSERT TABLE 3 HERE]}

Participants attributed their increased level of PA directly to participation in the WBA program. In addition to motivating participants to become physically active, although not emphasized in the program, some participants also felt the WBA program encouraged them to change their eating habits $65 \%, 19$ of 29 women responding to this interview question).

\footnotetext{
"It is part of my routine now and I push myself more. It just really changed, the nutrition part hit home, but the part that we were exposed to exercise really, really changed my participation in physical activity. ... they really honed in on if we were doing things right and showing us ways to do things."
}

Consistent with the quantitative analysis, at the time of the follow-up participants described some decline in their PA levels since the end of the program.

"No I was doing better than I am doing now. I was getting out more to walk and I was lifting weights. I did great during, and right after the book club. I have just decreased recently."

However, a small subset of women reported being more active since the program ended, thanks to the motivation that they gained during the program.

"I am a little more active now than in the program, because the book club helped bring out the importance of it. I think about it a little bit more than I did before." 


\section{Attitudes toward Physical Activity}

The most motivating factor for respondents was the physical benefit derived from being active $(77 \%, 24$ of 31 responding to attitude questions). Women frequently reported they wanted to be active in order to lose weight, get in shape, and generally improve their quality of life.

"I think definitely the health aspects of it. I have people that are 93 and still on the bike or walking. I think that as you age if you keep moving you don't have to depend on someone else as you get older. I hope it lengthens my life and I have a good quality of life in the end. I find that to be a big motivator for me."

In addition, many respondents also liked that being active had mental/emotional benefits (77\%, 24 of 31 women). They described feeling happier and having more energy to get more out of life.

"It makes me feel good. Just knowing you did it every day for your body makes you feel like a stronger woman. You just know that you are stronger because you are putting that time into making you feel healthier. I have felt depressed in my entire life, but now I feel like that whatever the day brings I am fine and I can do it."

The majority of respondents reported that their biggest barrier to PA was finding time to be active (84\%, 26 of 31 women). This was closely linked to the number of other priorities that compete for their limited time and attention, such as work and family commitments.

"It is still very hard to make myself a priority. It is a consistent barrier for me. I am always taking care of everyone else first, that comes natural for me. I have very little time to take care of myself, which should come naturally, but it doesn't."

Other women reported that a lack of motivation or accountability kept them from being as physically active as they would like to be. Various environmental issues, such as the weather in summer and winter, further inhibited their motivation to be physically active (23\%, 7 of 31 women).

"The motivation to get started each day [is a barrier]. It used to be a regular part of my life and once I stopped, it is really hard to get back into it. It is hard to think about it when it is not part of your regular routine."

Another barrier identified by some respondents was accessibility of fitness facilities (16\%, 5 of 31) and services (i.e., facility hours and physical proximity). Multiple women also mentioned that childcare needs impeded their ability to be active. A number of women said that physical constraints (i.e. injuries, pain associated with aging, and morning sickness) prevented them from being active and achieving their activity goals (35\%, 11 of 31 women that responded).

\section{Participant Self-Worth and Overcoming Barriers}

Self-worth significantly increased from baseline to follow-up ( $\mathrm{d}=1.6)$ and from post to follow-up $(d=1.47)[F(2,46)$ $=19.207, p<.0005$ ] (Table 3). From baseline to post $42 \%$ (10 out of 24) increased self-worth; from baseline to follow-up 75\% (18 out of 24) increased self-worth; from post to follow-up 71\% (17 out of 24) increased self-worth.

Participants' experiences shared during interviews reaffirmed this change. Women felt they were better able to prioritize themselves and had gained new confidence, both in their abilities to participate in PA and in other areas of their lives as well.

"I think the book club emphasized taking the time to exercise was something to do for myself. And with anything else I am trying to do that...The book club definitely stressed that we need to be active for ourselves."

"I feel more in control of my behavior. I am better able to make decisions, set goals, implement them and then change myself through achieving my goals. This has increased my self-esteem over the last year." 
Participants also provided detailed examples of the skills they had gained through the WBA program to overcome barriers to PA, such as learning the value of incorporating PA into their daily schedules by making small changes, or "baby steps."

"It has just convinced me that I just have to do it every day. It is as necessary a part of your schedule as brushing your teeth every day. Even though I may not enjoy it, it is better to move than not. I try to remind myself on a daily basis that if I get up and move I will feel better. I have improved my awareness and need to get up and move more. It has become a part of my routine in the last year."

Many respondents were continuing to use self-monitoring techniques, primarily the pedometer and journaling (57\%, 16 of 28). Approximately half of the respondents who reported not continuing to self-monitor said that they would like to start using the pedometer again.

"I really think that pedometer was a wonderful thing. I did it for quite a long while, but then I stopped. I think I will start again, because when I would glance at it I would realize it was a great motivator to get me to move more throughout the day...."

While participants' goals varied in intensity and specificity, almost half of the women believed that the program had improved their goal-setting ability (57\%, 17 of 30). Half of respondents reported that they had been successful at some level in achieving their goals (50\%, 11 of 22 that responded).

"We talked a lot about goal-setting and I guess I would say I just feel more in control. That goals don't have to be huge. They can be incremental, and I can be in charge of that."

The vast majority of respondents reportedly continue to be involved in a social support group. Some of the participants from the original WBA groups continue to meet. The availability of this type of social support has helped many women to feel less alone in their struggles to lead healthier lives.

"It was just so good to be with other women that were successful and working. Most of who seemed to struggle with weight issues or issues having to do with their self-worth. It was just good to sit and be able to talk with these people."

\section{Discussion}

This study used both qualitative and quantitative methodologies to investigate the impact of an innovative lifestyle based PA intervention on PA and self-worth in adult women. There was no contact between program facilitators and participants during the interim period (post-intervention to follow-up one year later).

Several women reported minimal PA at baseline but stated that their PA levels increased as a result of participation in WBA. However, impact of the program varied among participants at follow-up: low to moderate PA levels were reported. Our qualitative findings support our quantitative PA recall data that indicated PA levels increased during the intervention but returned to near baseline levels at the one year follow-up. This decrease in PA at follow-up suggests that the failure to provide minimal contact (or some type of support) from post intervention to follow-up may not be effective at promoting long-term PA adherence. Contrary to these findings, Segar and colleagues (2002) found PA was maintained with no interim contact between post-intervention and follow-up for a cognitive/empowerment intervention for women. Our findings are consistent with those of others reported in the literature; however, no interim contact was implemented in our study (Van Der Bij,Laurant, \& Wensing, 2002; Cox et al., 2008; Dunn et al., 1999). Cox and colleagues (2003) included telephone contact every 6 weeks (4 calls over 6 months) during follow-up (6-18 months) of an intervention. Adherence rates decreased in all groups (both center and home-based) over time. Taken together, these findings suggest that the ideal approach to increasing long-term PA adherence in women remains unclear. 
Although PA levels returned to near baseline levels at follow-up in the present study, our qualitative findings determined that women had increased awareness about PA. They also reported that they developed strategies to overcome barriers including time management and self-motivation techniques (e.g., pedometer use, journaling). These findings suggest that women had developed skill sets that support PA, however, they still had barriers (e.g., decreased social support at the end of an intervention, making PA a priority, other priorities such as work and family competing for time, and lacking strong motivation) that deterred participation in regular long-term PA. In a study by Segar and colleagues (2002) barriers related to finding time and prioritizing exercise were specifically addressed, and higher PA levels at both post intervention and follow-up were reported. In the future, the time spent during the book club intervention on barriers may be best spent specifically addressing barriers related to finding and maintaining social support and making PA a priority over other time commitments (family and work) to help women increase and maintain their PA levels.

Although PA did not increase over the long-term in the present study, self-worth increased progressively across the intervention and was still significantly increased at follow-up. Several researchers have reported a relationship between self-worth and PA participation (Elavsky, 2009; Huberty et al., 2008). Qualitatively, women also reported being happier, more energetic, with an increased desire to get more out of life. Although not assessed in the current investigation, self-efficacy may have played a role in increasing self-worth. McAuley and colleagues (2000) have suggested that self-efficacy and PA act in parallel to influence subdomains of esteem which act on physical selfworth which in turn act on global self-esteem. More studies that assess mediators of change in self-worth during and after PA promotion programs are needed.

Our qualitative findings suggested that opportunities for the development of social support were an important design component of WBA. Social support has been implicated in PA adoption and adherence (McAuley et al., 2003; Rhodes, 2001; White et al., 2005). Additionally, Crocker and Wolfe (2001) have identified social support (feedback from others, family support) as a contingency of self-worth. Women Bound to Be Active was specifically designed with a book club format to enhance social contact and support among participants. Facilitating long-term social support and understanding the relationship of social support to self-worth could be key to helping women maintain PA over time.

Although WBA was not a dietary intervention, one book was about eating and how individuals approach eating and their habits related to eating. It is important to note that this book did not provide structured dietary guidance.. Despite this approach, qualitative findings indicate that some women expressed general interest in pursuing nutritional modification and weight loss. During WBA, specific goals related to weight loss were not identified (e.g., the desire to lose a given number of pounds or achieve a specific BMI) and were not discussed or encouraged. Quantitatively, BMI significantly decreased from baseline to post intervention and was maintained at follow-up, suggesting that many women, although not discussed in the intervention, remained interested in focusing on weight loss rather than PA participation. Segar and colleagues (2008) have reported that PA is correlated with the type of goals women set. Women who focus on goals related to weight change and physical appearance are less likely to maintain PA than women who set goals related to well-being and stress reduction (Segar, 2008). The qualitative findings that women were motivated based upon weight loss, getting in shape, and improving quality of life suggests that overt de-emphasis of weight-related goals as used in this intervention may need to be combined with stronger emphasis and more specific guidance toward PA related goals to have a sustainable impact on goal setting and PA long-term. WBA program modifications are warranted and more research is needed in this area.

\section{Limitations}

This study had a number of limitations. First, PA was measured using a self-report instrument. Second, the PA recall tool used in our follow-up may not have been sensitive to reports of leisure, recreational, and/or lifestyle activities adopted by women as a result of this lifestyle based intervention. Other self-report tools to assess long-term PA in women should be explored. Also, combining the use of both subjective and objective measures of PA should be considered. Third, we did not include a control group which did not permit comparison to women who did not have an intervention. Future studies should include randomization to intervention and control groups with long-term follow-up. Fourth, this was a small, homogenous sample of women, limiting statistical power to detect differences, and generalizability, respectively. The small sample size may have particularly limited the detection of differences if confounding factors had been controlled. Fifth, the PA recall tool used may have severe limitations when used with women enrolled in a lifestyle-based intervention to promote PA. In the future, studies should use both objective and subjective measures of PA. Furthermore, because participants self-selected into this study, and 
some dropped out from the follow up analysis, the representativeness of the sample may have been further compromised, further limiting the generalizability of conclusions. Finally, because much of the data were selfreported, some participants may have reported their answers as they thought would be socially desirable.

\section{Future Research}

Future research should examine: 1) experimental designs that integrate qualitative and quantitative methodologies and promote long-term PA acquisition, 2) long-term longitudinal designs are warranted to determine the most efficacious PA promotion program for women, 3) studies with mixed designs intended to differentiate between ongoing intermittent contact or no contact with program participants could be useful in determining best practices for program follow-up in women, 4) the relationship between self-worth, BMI, and PA participation (combined qualitative and quantitative designs may be especially useful here), 5) mediators of changes in self-worth during a PA program, 6) innovative and effective strategies to enhance social support (i.e., book club "type" interventions, use of the internet to facilitate support), and 7) instruments designed to specifically measure PA in women.

\section{Conclusion}

This study used integrated quantitative and qualitative inquiry to determine the long-term effectiveness of an innovative lifestyle intervention on PA and self-worth in women. Although not effective in increasing PA long-term, the program did enhance long-term self-worth and supported weight management in a sample of healthy overweight/obese adult women. Women Bound to Be Active significantly increased short-term PA participation in these women through social support, increased awareness, and development of strategies to overcome barriers to PA. Although strategies to overcome barriers were developed, other barriers continued to deter women from PA adherence. This study supports the role of self-worth in weight management however, their relationship to PA adherence remains unclear and more research is warranted in this area. 


\section{References}

Ainsworth, B. (2000). Physical activity patterns in women. The Physician and Sports Medicine, $28(10), 2$.

Annesi, J.J. (2000). Effects of minimal exercise and cognitive behavior modification on adherence, emotion change, self-image, and physical change in obese women. Perceptual and Motor Skills, 91, 322-336.Berg, B.L. (2007). Qualitative Research Methods for the Social Science. (6 ${ }^{\text {th }}$ ed.) Boston, MA: Pearson Education, Inc.

Blair, S. N., Kohl, H. W., Gordon, N. F., \& Paffenbarger, R. S. Jr.(1992). How much physical activity is good for health? Annual Review of Public Health. 13, 99-126.

Bradley, B.H., Curry, L.A., \& Devers, K.J. (2007). Qualitative Data Analysis for Health Services Research: Developing Taxonomy, Themes, and Theory. Health Services Research, 42(4), 1758-1772.

Cox, K.L., Burke, V., Gorely, T.J., Beilin, L.J., \& Puddey, I.B. (2003). Controlled comparison of retention and adherence in women ages 40-65 years: The SWEAT study (sedentary women exercise adherence trial). Preventive Medicine, 36, 17-29.

Cox, K.L., Burke, V., Beilin, L.J., Derbyshire, M.J., Grove, J.R., \& Blanksby, B.A. et al. (2008). Short and longterm adherence to swimming and walking programs in older women: The sedentary women exercise adherence trial (SWEAT 2). Preventive Medicine, 46, 511-517.

Crocker, J., \& Wolfe, C. T. (2001). Contingencies of self-worth. Psychological Review, 108, 593-623.

Dunn, A., Marcus, B., Kapert, J., Garcia, M., Kohl, H. W., \& Blair, S. (1999). Comparison of lifestyle and structured interventions to increase physical activity and cardiorespiratory fitness. Journal of American Medical Association, 28I(4), 327-334.

Elavsky, S. (2009). Physical activity, menopause, and quality of life: the role of affect and self-worth across time. Menopause, 16(2), 265-271.

Epstein, L. H. \& Roemmich, J. N. (2001). Reducing sedentary behavior: Role in modifying physical activity. Exercise and Sports Science Reviews. 29, 103-108.

Eyler, A.A. \& Vest, J.R. (2002). Environmental, policy, and cultural factors related to physical activity in a diverse sample of women. The women’s cardiovascular health network project. Women \& Health, 36, 1-15. 
Gross, L.D., Sallis, J. F., Buono, M. J., Roby, J. J., \& Nelson, J. A. (1990). Reliability of interviewers using the 7day physical activity recall. Research Quarterly for Exercise and Sport, 61, 321-5.

Fox, K.R., (2000). Self-esteem, self-perceptions, and exercise. International Journal of Sports Psychology, 31(2), 228-40.

Hahn, R.A., Teuesch, S.M., \& Rothenberg, R.B. (1998) Excess deaths from nine chronic diseases in the United States. Journal of American Medical Association, 264(20), 2554-59.

Howley, E.T. \& Franks, B.D. (1992). Health fitness instructor's handbook: Health Status Questionnaire. Champaign: Human Kinetics.

Huberty, J.L., Vener, J., Sidman, C., Meendering, J., Blissmer, B., Schulte, L., Flohr, J., \& Ransdell, L.B. (2008). Women Bound to Be Active: A pilot study to explore the feasibility of an intervention to increase physical activity and self-worth in women. Women and Health, 48(1), 83-101.

Jacobs, D. R., Ainsworth, B., Hartman, T. J., \& Leon, A. S. (1993). A simultaneous evaluation of 10 commonly used physical activity questionnaires. Medicine and Science in Sports and Exercise, 25, 81-91.

King, A. C., Haskell, W. L., Young, D. R., Oka, R. K., \& Stefanick, M. L. (1995). Long-term effects on varying intensities and formats of physical activity on participating rates, fitness, and lipoproteins in men and women aged 50 to 65 years. Circulation, 91, 2596-2605.

Levy, S.S. \& Ebbeck, V. (2005). The exercise and self-esteem model in adult women: the inclusion of physical acceptance. Psychology of Sports and Exercise, 6(5), 571-84.

Marcus, B.H., Rossi, J.S., Selby, V.C., Niaura, R.S., \& Abrams, D.B. (1992). The stages and processes of exercise adoption and maintenance in a worksite sample. Health $\quad$ Psychology, 11(6), 386-395.

McAuley, E., Mihalko, S.L, \& Bane, S.M. (1997). Exercise and self-esteem in middle-aged adults: Multidimensional relationships and physical fitness and self-efficacy influences. Journal of Behavioral Medicine, 20(1), 67-83.

McAuley, E., Lox, C., \& Duncan, T. E. (1993). Long-term maintenance of exercise, self-efficacy, and physiological change in older adults. Journal of Gerontology, 48(4), P218-24.

McAuley, E. \& Blissmer, B. (2000). Self-efficacy determinants and consequences of physical activity. Exercise and Sport Science Reviews, 28(2), 85-88. 
McAuley, E., Jerome, G.J., Elavsky, S, Marquez, D.X., \& Ramsey, S.N. (2003). Predicting long-term maintenance of physical activity in older adults. Preventive Medicine, 37, 110-118.

McAuley, E., Morris, K. S., Motl, R. W., Konopack, J. F., \& Elavsky, S. (2007). Long-term follow-up of physical activity behavior in older adults. Health Psychology, 26(3), 375-80.

Messer, B. \& Harter, S.V. (1986). Manual for the adult self-perception profile. Denver: University of Denver Press.

Onwuegbuzie, A.J. \& Leech, N. (2005). Taking the “Q” out of research: Teaching research methodology without the divide between quantitative and qualitative paradigms. Quality and Quantity, 39, 267-296

Pope, C., Ziebland, S., \& Mays, N. Qualitative research in health care: Analysing qualitative data. BMJ, 320(7227), 114-6.

Rhodes, R., Martin, A., \& Taunton, J. (2001). Temporal relationships of self-efficacy and social support as predictors of adherence in a 6-month strength-training program for older women. Perceptual Motor Skills, 93(3), 693-703.

Saks, M., \& Allsop, J. (Eds.) (2007). Researching Health: Qualitative, Quantitative and Mixed Methods. London: SAGE Publications.

Segar, M., Jayaratne, T., Hanlon, J., \& Richardson, C.R. (2002). Fitting fitness into women’s lives: Effects of a gender-tailored physical activity intervention. Women's Health Issues, 12(6), 338-47.

Segar, M.L., Eccles, J.S., \& Richardson, C.R. (2008). Type of physical activity goal influences participation in healthy midlife women. Women's Health Issues, 18, 281-291.

Sonstroem, R.J. (1997). The physical self-system: A mediator of exercise and self-esteem. In K.R. Fox (Ed.), The physical self: From motivation to well-being (pp. 3-26). Champaign, IL: Human Kinetics.

Striphas, T. (2003). A dialectic with the everyday: Communication and cultural politics on Oprah Winfrey's book club. Critical Studies in Media Communication, 20(3), 295-316.

United States Department of Health and Human Services (1996). Physical activity and health: a report of the Surgeon General. Atlanta, GA: U.S. Department of Health and Human Services, Centers for Disease Control and Prevention, National Center for Chronic Disease Prevention and Health Promotion, 1996.

United States Department of Health and Human Services (2008). Physical Activity Guidelines Advisory Committee. Physical Activity Guidelines Advisory Committee Report, 2008. Washington, DC. 
Van Der Bij, A. K., Laurant, M. G., \& Wensing, M. (2002). Effectiveness of physical activity interventions for older adults: a review. American Journal of Preventative Medicine, 22(2), 120-33.

Wallston, K.A., Wallston, B.S., \& DeVellis, R. (1978). Development of the multidimensional health locus of control scale. Health Education and Behavior, 6(1), 160-170.

White, J. L., Ransdell, L. B., Vener, J., \& Flohr, J. (2005). Factors related to physical activity adherence in women: Review and suggestions for future research. Women and Health, 41, 123-148.

Wilbur, J., Miller, A.M., Chandler, P, \& McDevitt, J. (2003). Determinants of physical activity and adherence to a 24-week home-based walking program in African American and Caucasian women. Research in Nursing \& Health, 26, 213-224. 
Table 1. Women Bound to Be Active (WBA) One-Year Follow-Up Questions

1. Why did you originally sign up for Women Bound to Be Active?

2. Now that it has been 12 months since you last participated in WBA, what would you say was the most rewarding part of the program or your favorite part?

3. What were your expectations when you signed up for the program? Were they met?

4. What was the most important thing you learned in WBA about your current physical activity level?

5. How you would personally define your participation in physical activity right now?

6. Before WBA how would you have defined your participation in physical activity?

7. How would you define your physical activity levels during WBA?

8. What are some factors that have contributed to you being less active than you would have wanted to be?

9. How do you feel/think WBA has change your participation in physical activity?

10. Do you think the program was able to change your perception on physical activity? Explain.

11. What do you like about physical activity? What do you dislike about physical activity?

12. What self-monitoring techniques are you still using if at all?

13. Over last 12 months, what would you list as the top physical activity you performed?

14. What was the main motivating factor to get you to be physically active?

15. If you don't get to exercise as much you like, what do you perceive to be a consistent barrier?

16. How did WBA help you overcome some of your consistent barriers?

17. Are there any barriers that you face that WBA did not cover? 
18. Do you think WVA was able to change your abilities to set goals? Explain.

19. Do you set physical activity goals for yourself and what are they?

20. Do you feel successful at reaching your personal goals?

21. Are you currently accessing any types of social support?

22. Do you have any examples of how you are now able to break through barriers because of WBA?

23. Do you feel as if WBA was able to change your feelings of self worth? Explain.

24. Are you able to attribute any other lifestyle changes to WBA?

25. What aspect of the program would you have liked to see done differently? 
Table 2. Demographic Characteristics of Participants

\begin{tabular}{lll}
\hline WBA Participants & & Follow up Participants (1 yr from end of intervention) \\
\hline $\mathrm{n}$ & 45 & 35 \\
Age (years) Mean (SD) & $48.1(10.8)$ & $50.6(11.7)$ \\
Caucasian (\%) & $41(91)$ & $32(91)$ \\
African American (\%) & $2(4.5)$ & $2(6)$ \\
Ethiopian American (\%) & $2(4.5)$ & $1(3)$ \\
\hline
\end{tabular}


Table 3. Means, Ranges and Standard Deviations for Outcome Variables

\begin{tabular}{|c|c|c|c|}
\hline & $\mathrm{BMI}$ & $\begin{array}{l}\text { Self-Worth } \\
\text { (possible range) }\end{array}$ & $\begin{array}{l}\text { 7-day recall } \\
\text { (kcals/kg/day) }\end{array}$ \\
\hline $\mathrm{n}$ & 24 & 24 & 23 \\
\hline Time 1 (baseline) & $28.70 \pm 7.16$ & $2.54 \pm .32$ & $32.57 \pm 2.24$ \\
\hline $\begin{array}{l}\text { Time } 2 \text { (post intervention - } 8 \\
\text { months) }\end{array}$ & $27.74 \pm 7.00$ & $2.60 \pm .21$ & $35.38 \pm 2.34$ \\
\hline $\begin{array}{l}\text { Time } 3 \text { (follow-up - } 20 \\
\text { months) }\end{array}$ & $27.4 \pm 6.68$ & $3.26 \pm .60$ & $33.98 \pm 2.10$ \\
\hline Range Time 1 (min - max) & $20-50$ & $1.50-3.0(1.0-4.0)$ & $24.54-35.39$ \\
\hline Range Time 2 (min - max) & $20-49$ & $2.17-3.0(1.0-4.0)$ & $32.46-42.11$ \\
\hline Range Time 3 (min - max) & $21-49$ & $1.83-4.0(1.0-4.0)$ & $28.50-40.43$ \\
\hline $\mathrm{ES}^{\mathrm{a}} \mathrm{T} 1^{\mathrm{b}}$ to $\mathrm{T} 2^{\mathrm{c}}$ & .83 & NS & 1.36 \\
\hline $\mathrm{ES} \mathrm{T} 2$ to $\mathrm{T} 3^{\mathrm{d}}$ & NS & 1.47 & NS \\
\hline ES T1 to T3 & 1.10 & 1.6 & NS \\
\hline
\end{tabular}

${ }^{\mathrm{a}} \mathrm{ES}$ - Effect size

${ }^{\mathrm{b}} \mathrm{T} 1$ - Time 1

${ }^{\mathrm{C}} \mathrm{T} 2$ - Time 2

${ }^{\mathrm{d}} \mathrm{T} 3$ - Time 3 
Figure 1. Flow chart for participants of study

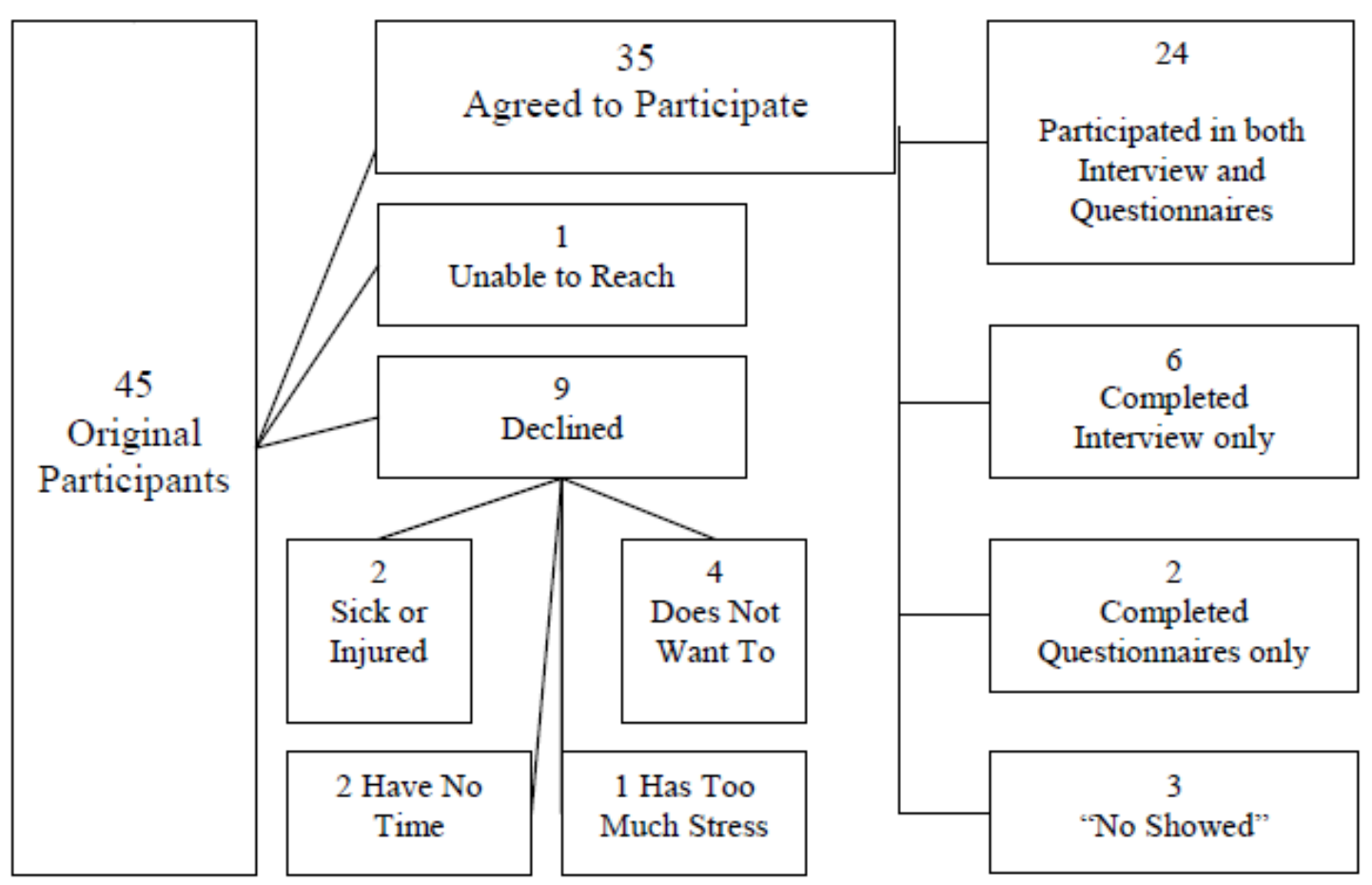

